\title{
Los Comentarios Reales y la Historicidad de lo Imaginario
}

Por más de un siglo los Comentarios reales (1609-1617) del Inca Garcilaso de la Vega (1539-1616) han sido objeto de valoraciones y pesquisas de todo tipo, pero es evidente que la historiografía americana sigue considerándolos como tex to de signo contradictorio. ${ }^{1}$ En definitiva creo que si la narración aún suscita interpretaciones conflictivas es porque el mensaje de la obra rebasa con mucho la función meramente documental que le atribuye el empirismo erudito. Dicho con la mayor sencillez, los Comentarios exigen un criterio estimativo que considere el sentido plurivalente de la obra, y creo que al practicar una lectura de esa indole el texto debe mantenerse en el marco histórico-literario de que procede.

Como punto de partida es indispensable reconocer que la escritura del Inca remite a una crisis personal y a un proceso de formación sin precedentes. Garcilaso no sólo es el primer escritor mestizo sino que es el primero que disfruta en toda su plenitud la cultura del Renacimiento y también la del imperio incaico. Pero si su equipo intelectual de primer orden era europeo, su referente vital siempre fue América. Esa contraposición de valores y espacios culturales adquiere un sentido cada vez más conflictivo en su obra debido al status incierto que padecǐa Garcilaso. Su familia paterna figuraba entre las más ilustres de España; su madre fue una princesa inca, pero él era mestizo y bastardo y como tal osciló angustiosamente entre los extremos culturales que configuraron su personalidad. De hecho la tensión y la variedad de recursos que intervienen en su escritura hacen de los Comentarios un tex to excepcional. Ante esas consideraciones me parece ingenuo insistir una vez más en controversias que afirman o desvirtúan la historicidad del texto en términos categóricos. ${ }^{2}$ Lejos 
de toda polémica lo que me he propuesto es examinar las razones y antecedentes que motivan la dimensión imaginativa del texto para, de esa manera, elucidar el sentido histórico que la creación literaria asume en los Comentarios. ${ }^{3}$

El repaso de la información biográfica revela de inmediato que los Comentarios fueron, de una manera u otra, el hecho central en la trayectoria de Garcilaso. ${ }^{4}$ La narración, que él trabajó laboriosamente, viene a ser el espacio en que convergen los itinerarios azarosos de su autor. Toda su vida puede verse, en efecto, como un gran esfuerzo de recopilación y lecturas que finalmente quedarian resumidas en su obra principal. Inclusive en las primeras noticias que ofrecen los Comentarios se descubre que el interés de Garcilaso por la historia data de sus años infantiles en Cuzco: "Es asĩ que residiendo mi madre en el Cozco, su patria, venian a visitarla casi a cada semana los pocos parientes y parientas que de las crueldades y tiranías de Atahualpa, como en vida contaremos, escaparon." Y luego añade: "En estas pláticas yo, como muchacho, entraba y salía muchas veces donde ellos estaban, y me holgaba de las oir, como huelgan los tales de oir fábulas." (I, I, cap. XV) ${ }^{5}$

Es fácilmente demostrable que desde su infancia Garcilaso sintió una especial fascinación ante el misterio de las cosas viejas y olvidadas. Ese embeleso juvenil se evocará una y otra vez en el curso de la narración: "En este tiempo tuve noticia de todo lo que vamos escribiendo, porque en mis niñeces me contaban sus historias como se cuentan las fábulas a los niños." (I, I, cap. XIX) Se trata claramente de experiencias y evocaciones que a menudo suscitan la nostalgia y los recuerdos de su niñez peruana. Garcilaso relata, por ejemplo, la conversación que sostuvo con un tío materno al que preguntaba "¿noticias tenéis del origen y principio de nuestros reyes?" A lo que el Inca mayor contestó: "Sobrino, yo te las diré de muy buena gana: a ti te conviene oirlas y guardarlas en el corazón, es frase de ellosaclara Garcilaso-por decir en la memoria." (I, I, cap. XV)

Hoy, al examinar los Comentarios y la peculiar formación del Inca, es imprescindible tener en cuenta que los primeros contactos que Garcilaso tuvo con la historia y la ficción se remontan a la tradición oral de los incas. Ese conocimiento inicial de un pasado que era a la vez histórico y legendario, se afirmó desde sus primeros años en los hilos de narraciones inmemoriales que Garcilaso guardó para siempre en su memoria prodigiosa. No se trata, como podria supo- 
nerse, de experiencias casuales o pasajeras. La prueba de ello está en que muchos años después, en la vejez, el Inca transformará gran parte de aquellas leyendas y recuerdos en materia primordial de su relato. Esa manera de recuperar el pasado me parece especialmente significativa al juzgar la hechura del texto y la concepción personal de la historia a que se atiene el Inca. Pero repárese que si subrayo la importancia de esas vivencias iniciales es porque creo que ellas inician y fecundan el trasfondo imaginativo de los Comentarios. A primera vista esas relaciones nos parecen simples fábulas ancestrales de un pasado brumoso, pero es obvio que Garcilaso no las vio de esa manera. El Inca intuyó correctamente que en ese corpus de narraciones estaba sedimentada una concepción antiquísima de la historia y de la vida misma. Como Herodoto y Tucídides muchos siglos antes, Garcilaso comprendió con agudeza ejemplar que el valor de aquellas fábulas no radicaba en la historicidad rigurosa de lo narrado. Apoyándose tanto en sus conocimientos historiográficos, como en su intuición, Garcilaso entendió que en el mito y la leyenda subyace una vivencia colectiva y un concepto de la sabiduría que sì puede tener sentido histórico; es por ello que afirma: "Y aunque algunas cosas de las dichas y otras que se dirán parezcan fabulosas, me pareció no dejar de escribirlas por no quitar los fundamentos sobre que los indios se fundan para las cosas mayores que de su imperio cuentan." (I, I, cap. XIX) 6

Estimo que esa observación de Garcilaso es de suma importancia, entre otras razones, porque confirma en las etapas iniciales del texto, el valor que el Inca implícitamente confiere a la experiencia imaginativa como testimonio histórico. Pero Garcilaso, experto como era en los quehaceres de la historia y alerta a posibles objeciones, no vacila en añadir con sesgo irónico: "porque en fin de estos principios fabulosos procedieron las grandezas que en realidad de verdad posee hoy España; por lo cual se me permitirá decir lo que conviniere para la mejor noticia que se pueda dar de los principios, medios y fines de aquella monarquía, que yo protesto decir llanamente la relación que mamé en la leche." (I, I, cap. XIX) ${ }^{7}$

Además, ya en el capitulo anterior, Garcilaso no sólo defiende su visión de la historia y su manera de proceder sino que-con osadía inesperada-contrasta, en igualidad de condiciones, las fábulas de los incas, las del mundo clásico y las sagradas escrituras.

$\mathrm{Y}$ de esta manera son todas las historias de aquella antigüedad; y no hay que espantarnos de que gente que no tuvo letras con que conservar la memoria de sus anti- 
guallas, trate de aquellos principios tan confusamente; pues los de la gentilidad del mundo viejo, con tener letras y ser tan curiosos en ella, inventaron fábulas tan digna de risa, y más que estotras, pues una de ellas es la de Pirra y Deucalión, y otros que pudiéramos traer a cuenta, y también se pueden cotejar las de la una gentilidad con las de la otra, que en muchos pedazos se remedan, y asimismo tienen algo semejante a la historia de Noé, como algunos españoles han querido decir, según veremos luego. Lo que yo siento de este origen de los incas diré al fin.

Guiado por una visión intensamente personalizada y a la vez sincrética de la historia, Garcilaso admitirá en su texto la experiencia imaginaria como fuente documental. ${ }^{8}$ Pero aunque asĭ sea, no quiero inferir de ninguna manera que Garcilaso manipuló indiscriminadamente los materiales que tuvo a su alcance. Veremos al situarnos en su contexto que el Inca, al aprovecharse de leyendas y fuentes literarias, lo que hace no es más que retomar los procedimientos que habỉa practicado la historiografía renacentista. 9 Procedimientos que eran, además, afines a su sensibilidad y a la vocación de narrador que él exhibe a lo largo de su obra. En un plano más inmediato se verá que si el texto gravita hacia una visión cada vez más individualizada de los hechos es porque Garcilaso no reprime evocaciones intimas; de hecho su obra toma como punto de partida una proyección autobiográfica que gradualmente condiciona todos los planos de su escritura. En general, esa tesitura vitalista de su lenguaje-"lo que yo siento," decía él-invita la presencia del material legendario como información y como núcleos imaginativos que adornan e impulsan el flujo del discurso. Es decir, que la leyenda en sus diversas formas surge, a un mismo tiempo, desde consideraciones informativas $y$ retóricas. El texto verifica a menudo esa doble función del relato imaginario: "Y para que la historia no canse tanto-dice Garcilasohablando siempre de una misma cosa, será bien entretejer en las vidas de los reyes Incas algunas de sus costumbres, que serán más agradables de oir que no las guerras y conquistas, hechas casi todas de una misma suerte; por tanto, digamos algo de las ciencias que los incas alcanzaron." (I, II, cap. XX)

En los libros que siguen, y con propósitos similares, Garcilaso inserta en su relación una extensa variedad de relatos que abarcan tanto la anécdota marginal como el esquema refinado de la novella de aventuras. Son narraciones que muy aparte de su mérito literario, sirven al narrador como núcleos que particularizan la experiencia 
inmediata y personal en el vasto panorama de la obra.10 En el esquema narrativo de los Comentarios esos cuentos actúan además como una sucesión de aperturas imaginativas que muestran oblicuamente la interioridad del proceso histórico y que al mismo tiempo ponen en evidencia los estratos disímiles que conforman el discurso narrativo.

Pienso que al valorar la dimensión creativa en los Comentarios siempre conviene tener presente que Garcilaso llegó a la historia a través de la literatura. Y si bien es cierto que en edad madura el Inca condena las fabulaciones caballerescas, cuidémonos de aceptar esa censura al pie de la letra. Tan comunes eran declaraciones y protestas de esa índole en el siglo XVI que llegaron-sobre todo entre erasmitas-a convertirse en una manida tópica literaria que se amparó en los convencionalismos moralizantes de la época. ${ }^{11}$ Hoy sabemos-por el inventario póstumo de su biblioteca-que el Inca guardó hasta el fin de sus días numerosas obras poéticas y de ficción. Además de La Celestina, conservó el Guzmán de Alfarache, el Decamerón de Boccacio, Las cien novelas de Juan Bautista Giraldi, obras de Dante, el Orlando enamorado de Matteo Marla Boiardo y muchas otras. Es cierto, sin embargo, que la literatura de creación no es lo que predomina en el inventario, pero es obvio al mismo tiempo que no todo lo que el Inca leyó figura en ese registro precario de sus libros. 12

De cara al texto, la elaboración a menudo exquisita del lenguaje corrobora por sí misma la poetización del discurso y pone al descubierto un amplio sector de referencias textuales. El escrutinio de la redacción demuestra, entre otras cosas, que los Comentarios se comportan como un amplio espacio intertextual que remite a dos niveles fundamentales: al proceso histórico visto desde las experiencias personales de Garcilaso y al mundo de los libros. Con propósitos muy diferentes el Inca regresa una y otra vez a las relaciones de Gómara, Cieza de León, el Palentino y Zárate para cuestionar la información o para glosarlas con una minuciosidad casi obsesiva.

Todo lo que hemos dicho-comenta Garcilaso-del tesoro y riquezas de los Incas, lo refieren generalmente todos los historiadores del Perú, encareciéndolas cada uno conforme a la relación que de ellas tuvo. Y los que más a la larga lo escriben son Pedro Cieza de León, capĭtulo XXI, XXXVII, XLI, XLIV y XCIV, sin otros muchos lugares de su historia. $Y$ el contador general Agustín de Zárate, libro primero, capítulo XIV donde dice estas palabras: "Tenían 
en gran estima el oro porque de ello hacían el rey y sus principales sus vasijas para su servicio, y de ello hacian joyas para su atavio, y lo ofrecian en los templos, y traía el rey un tablón en que se sentaba de oro de dieciséis quilates, que valió más de veinticinco mil ducados, que es el que don Francisco Pizarro escogió por su joya al tiempo de la conquista." (I, VI, cap. II)

Para ilustrar con mayor precisión el contexto en que fueron redactados los Comentarios, conviene tener presente que en tiempos de Garcilaso las relaciones oficiales ya estaban escritas y que el Inca no podía desentenderse de esas crónicas prestigiosas que debǐan ser en todo momento referente obligatorio y la pantalla sobre la cual él proyecta su narración. Pero el registro de sus fuentes escritas no se limita a relaciones de otros cronistas. En segmentos muy numerosos la narración convoca además, la presencia de textos disímiles que de forma inesperada aparecen en la escritura de Garcilaso. Se alude con igual naturalidad a la historiografía y a la literatura italiana; en particular a la obra de Francesco Guicciardini (II, I, cap. II), al Orlando furioso de Ariosto (II, VII, cap. XXVIII), asĩ como a las Vidas paralelas de Plutarco (II, III, cap. VIII) entre muchos otros. 13 Como antes lo hiciera en la Florida (1605), en los Comentarios Garcilaso acude, más de una vez, al caudal informativo que han de proporcionarle los textos literarios. Sin mayores vacilaciones el Inca emplea como fuentes documentales, las Elegias de varones ilustres de Indias de Juan de Castellanos y también La araucana de Alonso de Ercilla. 14

En ese repertorio de textos importa reconocer que los modelos literarios que Garcilaso cita asumen un doble papel: son fuente documental y a la vez modelo de expresividad. Esa amplitud de criteriofrencuente en la historiografía clásica y renacentista-permitia a su vez una manipulación más amplia de la materia documental según puede verificarse en el Methodus ad facilem historiarum cognitionem de Jean Bodin que Garcilaso consultó.

Pero no quiero sugerir que la dimensión imaginativa de los Comentarios se corrobora exclusivamente por medio de citas ocasionales, glosas o en trozos que resaltan por su delicadeza y refinamiento estilisstico. Más significativo aún son los pasajes en que la evocación del texto literario condiciona la naturaleza misma del hecho histórico que se narra. De todos los ejemplos que pueden ofrecerse para documentar esa transposición imaginativa en el dis- 
curso de la historia, el más obvio y conocido aparece en los capítulos que describen la conducta caballeresca de guerreros incas.

Este nombre huaracu es de la lengua general del Perú; suena tanto como en castellano armar caballero; porque era dar insignias de varón a los mozos de la sangre real, y habilitarlos, asi para ir a la guerra como para tomar estado. Sin las cuales insignias no eran capaces ni para lo uno ni para lo otro, que como dicen los libros de caballerias eran donceles que no podian vestir armas. (I, VI, cap. XXIV)

En el capitulo siguiente el Inca continúa:

Sin estas armas los examinaban en todas las demás que ellos usaban en la guerra para ver la destreza que en ellas tenian. Hacianles velar en veces diez o doce noches, puestos como centinelas para experimentar si eran hombres que resistían la fuerza del sueño. ${ }^{15}$

Esa curiosa aparición del mundo caballeresco en la civilización incaica confirma la vigencia del referente literario en la escritura del Inca. Pero ese recurso narrativo no es en sǐ un procedimiento arbitrario ni debe sorprendernos si recordamos que Garcilaso descubrió sus facultades de escritor en los rigores de la literatura de creación. Su hermosa traducción de los Dialoghi de Amore (1590) de León Hebreo se reconoce ante todo como una exquisita reelaboración del texto original y también como ejercicio decisivo en la formación filológica del Inca. La traducción equivale, en efecto, al taller en que Garcilaso comenzó a refinar su imaginación creadora y puede verse además como el reto que le estimuló a diversificar su registro de lecturas. ${ }^{16} \mathrm{El}$ Inca confiesa que al emprender la traducción se sintió atraỉdo por "la suavidad y dulzura de su filosofia."17 Y es lógico suponer que a partir de esa labor primeriza, Garcilaso verá el lenguaje como sistema de comunicación y a la vez como materia susceptible de convertirse en creación artística.

El texto de León Hebreo, aparte de ser una prueba ardua, fue el resorte que, de manera definitiva, vinculó al Inca con el pensamiento neoplatónico que se habia difundido en España en obras tales como el De amore de Marcilio Ficino, Il Cortegiano de Castiglione y en otros libros que el Inca conoció. 18 Esos textos, lejos de ser mero deleite, penetraron en los Comentarios para formar la perspectiva sincrética, la visión armónica del universo y las formulaciones refinadas que predominan en la prosa del Inca. En fin de cuentas de 
su compenetración con los Diálogos de amor surge el uniformismo histórico que Garcilaso a su vez ingeniosamente enlaza con la visión imperial y teocéntrica de la historia que aún defendỉa España. Visión que el Inca exalta-en parte por razones personales-con la vehemencia del converso: "Y a los que todavia imaginaren que hay muchos mundos, no hay para qué responderles, sino que se estén en sus heréticas imaginaciones hasta que en el infierno se desengañen de ellas." $(I, I, \text { cap. I })^{19}$

En la narración del Inca las huellas de sus primeras experiencias, y en particular de su formación literaria, serán evidentes en planos muy disìmiles. Ya en la Florida, como lo ha señalado Aurelio Miró Quesada, Garcilaso "intercala, dentro de la veracidad general de su historia, expresivos aspectos novelescos." (Libro VI, cap. XIX) Y seguidamente añade el mismo crítico: "Son escenas de novela bizantina, al principio (el Inca tenla entre sus libros la Historia Etiópica de Teágenes y Cariclea, de Heliodoro): con pérdidas, encuentros, naufragios, reconciliaciones, desventuras."20

No es necesario insistir en un cotejo minucioso de citas para confirmar que la visión histórica de Garcilaso tiene raíces muy profundas en la experiencia imaginativa. En ese sentido no exageraba el historiador peruano Raúl Porras Barrenechea al subrayar que "Garcilaso cultivó pues, una forma histórica que concede valor a las creaciones poéticas y a las concepciones mágicas y vagorosas del alma popular."21 A cualquier nivel de su obra es evidente que el pensamiento histórico del Inca está modelado por una sensibilidad predispuesta a la creación. Por ser asî, al considerar la importancia de los Diálogos de amor en la formación de Garcilaso, debemos tener presente que traducir, pero en una latitud mucho más amplia, fue lo que hizo el Inca en la Florida y también en los Comentarios. 22 En la Europa del siglo XVI, Garcilaso era el primero que traducía-con su peculiar visión de mestizo-una de las principales culturas prehispánicas. Y la consistencia de su esfuerzo se verifica en que la redacción de los Comentarios toma la interpretación del quechua como punto de partida. 23 En realidad su texto surge a partir de consideraciones filológicas que trascienden el propósito meramente descriptivo que se anuncia en las primeras páginas.

Pero es necesario aclarar que la materia ficcionalizada en los Comentarios no emana exclusivamente de la sensibilidad literaria del Inca. Lo cierto es que esa concepción creativa de la historia se exaltó en los modelos historiográficos que autorizan e inspiran la narración 
de Garcilaso. Sin insistir demasiado en los antecedentes formales y teóricos que informan su obra, vale la pena recordar, por ejemplo, que Cicerón-autor que figuraba en la biblioteca del Inca-había integrado ya en el concepto de narratio formas variadas del discurso como fabula, argumentum e historia. ${ }^{24}$ Siglos después, en la Edad Media, esa zona de convivencia formal entre la fabulación y la historia se dilatará aún más. La presión doctrinaria y ejemplarizante que impuso la tradición bủblica, exigìa de la historia y la ficción una postura ética y narrativa muy similar. Bien sabemos que para la historiografía medieval-y en menos grado para la renacentista-la verosimilitud de lo narrado remite en última instancia a una concepción dogmática y providencialista de los hechos. ${ }^{25}$ La relación histórica aparece de ese modo en función de creencias codificadas que siempre estarán por encima de la naturaleza misma de los acontecimientos narrados. Ocurre entonces que la fundamentación filosófica de la historia queda sujeta a un sistema de creencias que interpreta los hechos desde su significación teológica. A partir de ese criterio la labor del teólogo y el historiador son equivalentes en varios órdenes. Piénsese, por ejemplo, que tanto la historia como la parábola eran suceptibles a una interpretación alegórica. En su base, ese ajuste fue posible debido a que el pensamiento medieval y aún el de la Contrarreforma concibió la historia, la filosofía y la ética como ciencias complementarias. La transcendencia de esa perspectiva histórica en el siglo XVI puede verificarse oblicuamente en un contex to anecdótico. Me refiero a la respuesta que Antonio de Guevara ofrece ante los reproches que le hacía el humanista Pedro de Rua, "¿A qué se ha de dar fé? - dice Guevara- ¿Dónde está el límite entre verdad y ficción cuando se sale de la firmeza de las letras sagradas?"26

Bien sabemos que esa concepción teocéntrica de la historia aún estaba vigente en el ámbito intelectual de Garcilaso. Las crónicas medievales de Castilla que el Inca consultó fueron modelos prestigiosos para él y para sus antecesores. $27 \mathrm{Y}$ aunque es cierto en términos generales que Garcilaso se inclinará cada vez más hacia el ideal artǐstico de la historia que postuló la historiografỉa italiana, no puede negarse, sin embargo, que en su esquema general los Comentarios son fieles en muchos órdenes fundamentales a los preceptos de la historiografía medieval. Esa pauta es evidente, a primera vista, en la noción que Garcilaso reiteradamente afirma de la "república cristiana" y en su postura agustiniana que le lleva a describir el imperio incaico en general como etapa preparatoria para la evangelización del Perú (I, VII, cap. IX). Además la visión histórica de Garcilaso mantiene casi intacto el plan providencialista que se habia difundido en la 
Preparatio evangélica de Eusebio de Casarea y que el Inca pudo asimilar por su cuenta en De Civitate Dei de San Agustín y en la De Monarquia de Dante. 28

La historia medieval al cimentar la verosimilitud en el dogma podia permitirse el uso arbitrario de la materia fabulosa. Hecho que explica, en parte, las distinciones imprecisas que entonces abundaban entre hagiografia e historia. Sirva como ejemplo sobresaliente el prestigio histórico que disfrutó por siglos la leyenda de Baarlam y Josaphat. Ese modo de concebir la realidad histórica como extensión imaginativa de creencias la comento aquí porque reaparece con sorprendente vitalidad en los Comentarios. Creo que sólo a la luz de esa tradición puede justificarse el relato en que Garcilaso narra con toda naturalidad, la intervención milagrosa del apóstol Santiago para impedir la derrota de los españoles en Cuzco.

A esta hora y en tal necesidad, fue Nuestro Señor servido favorecer a sus fieles con la presencia del bienaventurado Apóstol Santiago, patrón de España que apareció visiblemente delante de los españoles, que lo vieron ellos y los indios encima de un hermoso caballo blanco, embrazada una adarga, y en ella su divisa de la orden militar, y en la mano derecha una espada que parecía relámpago, según el resplandor que echaba de sí. Los indios se espantaron de ver el nuevo caballero y unos y otros decían: "Quién es aquel Viracocha que tiene la illapa en la mano" (que significa relámpago, trueno y rayo) ... Con lo cual los españoles se esforzaron y pelearon de nuevo, y mataron innumerables enemigos, sin que pudiesen defenderse, y los indios acobardaron de manera que huyeron a más no poder y desampararon la pelea. (II, II, cap. XXIV)

Pero es claro que esas proyecciones imaginativas no siempre derivan de fuentes medievales. La visión retórica que se sobrepuso al proceso histórico emana, en último análisis, de textos clásicos que habian favorecido interpretaciones alegóricas de la realidad con el fin de reconciliar el mito y la razón. En los Comentarios un ejemplo significativo de esa manera de ver la historia se ofrece en el discurso que pronuncia el Inca Manco al ser restituido a su cargo. Arenga que se insinúa como semblanza imaginaria y que dicho sea de paso, surge repleta de ironías y acusaciones veladas contra las maniobras de la política imperial española. Garcilaso, siguiendo de cerca a sus modelos clásicos, construye el discurso según los cánones de la 
oratoria que pudo haber asimilado en la Historia de la guerra del Peloponeso de Tucídides y la Historia de Roma de Polibio. ${ }^{29}$ Son artificios retóricos que se perciben sin dificultad. "Ahora veo cumplida por entero la profecía de mi padre Huaina Cápac, que gentes no conocidas habìan de quitarnos nuestro imperio, destruir nuestra república y religión." Y más adelante añade, "Lo uno y lo otro ha salido verdad, pues que luego que ellos entraron en nuestro imperio enmudecieron nuestros oráculos que es señal que se rindieron a los suyos." (II, II, cap. XXIX)

Según ya lo ha demostrado Marcel Bataillón, esas áreas de contacto entre la narración ficticia y la historia serán aun más extensas en el siglo XVI. En El libro áureo de Marco Aurelio de Fray Antonio de Guevara esa confluencia del material legendario y los hechos verificables tiene uno de sus ejemplos más notables. Américo Castro, entre otros, ha señalado que el utopismo intelectual del siglo XVI provocó innumerables controversias y pronunciamientos que se empeñaron inútilmente en establecer límites precisos entre la fabulación y la historia. 30 En líneas generales, se trata de planteamientos teóricos motivados por las formulaciones aristotélicas en torno al carácter de lo verosìmil y de lo general y particular en la poesỉa. 31 Garcilaso por su cuenta tuvo acceso a obras entre las que figuran: Della Rettorica di Aristoteli tradotta (1571) de Alessan-Piccolomini y la Dialéctica de Boecio. Es de esperar que esas especulaciones de los comentaristas dejaran huella fresca en la obra del Inca. De hecho, al referirse a la Araucana, indirectamente Garcilaso insiste en que esas relaciones, "según las escriben en verso los poetas de aquellos tiempos, que fuera mejor escribirlas en prosa, porque fuera historia y no poesia y se las diera más crédito." (II, VIII, cap. XIII) En el siglo XVI esos mismos razonamientos encontraron eco tanto en la obra de tratadistas como en la misma narrativa de ficción. 32 Son de interés en ese orden las aclaraciones que don Quijote hace al canónigo de Toledo al admitir que "tanto la mentira es mejor cuanto más parece verdadera." O cuando añade,

Hanse de casar las fábulas mentirosas, con el entendimiento de los que las leyeren, escribiéndose de suerte que facilitando los imposibles, allanando las grandezas, suspendiendo los ánimos admiren, suspendan, alborocen y entretengan de modo que anden a un mismo paso la admiración y la alegrìa juntas; y todas estas cosas no podrá hacer el que huyere de la verosimilitud y de la imitación, en quien consiste la perfección de lo que se escribe. ${ }^{33}$ 
De igual manera en su primera carta a Maximiliano de Austriaque precede a los Diálogos de amor, Garcilaso deja entrever la raǐz neoaristotélica de sus juicios literarios. "Que es mejor-dice el Inca al describir las relaciones históricas-hazellas mal hechas que dexallas de hazer: pues son historia y no poesĩa: la cual no sufre medianía alguna." 34 Todo el registro teórico y las contradicciones implícitas en esas formulaciones han sido resumidas con admirable claridad por Marcel Bataillón al señalar entre otras cosas, que "la novela para la cual reservan su aficción los erasmistas [ que con tanta vehemencia censuraron la ficción caballeresca] es la novela bizantina de aventuras, la Historia etiópica de Teágenes y Cariclea," 35 obra que Garcilaso contaba entre sus libros y que obviamente influyó en la composición novelesca de la Florida del Inca (Véase: Primera parte, II, cap. 14).36 "Esta novela-agrega Bataillón-les agradó por mil cualidades que faltan demasiado en la literatura caballeresca: verosimilitud, verdad sicológica, ingeniosidad de composición, sustancia filosófica, respeto de la moral." 37

En ese ámbito de formulaciones indecisas, es notable el rigor conceptual y metodológico que mantuvo el Inca al construir su narración. Su manera de proceder es admirable, sobre todo, si se toma en cuenta que los deslindes formales entre la ficción y la historia eran escasos y casi siempre borrosos. Relaciones falsas, como lo fueron los Libros plúmbeos, habían sido reconocidas como documentos históricos en la corte de Felipe II. En ese orden, es curioso también que Alonso Barros al comentar el Guzmán de Alfarache, celebrara la obra de Mateo Alemán "por su admirable disposición y observancia de lo verosímil de la historia; el autor ha conseguido felicisimamente el nombre $y$ oficio de historiador." 38 Ante la naturaleza de esos juicios no puede sorprendernos que obras de extraordinaria riqueza imaginativa, como lo son Os Lusiadas y la Gerusalem Liberata de Tasso, también hubiesen reclamado el rigor y los méritos de la narración histórica. 39 Resulta claro, por otra parte, que los Comentarios reales no pueden ubicarse en ese espacio confuso al que pertenecen entre otros, El relox de principes de Antonio de Guevara. 40 En conjunto la obra del Inca asume en su disposición y propósitos, rasgos concretos que la definen como narración histórica de considerable valor documental. Pero al mismo tiempo sería igualmente arbitrario atenuar los vinculos que la narración mantiene con la literatura de creación. Siempre es preciso tener en cuenta que el caudal imaginativo de los Comentarios y lo que deben a la narrativa de ficción. no es en ningún sentido impropio en la historiografìa del 
siglo XVI. La obra del Inca comparte, con muchos textos de su época, esa latitud indecisa en que lo imaginario con frecuencia trasciende los hechos verificables. En términos retóricos esa manera de proceder remite a la supraveritatem; figura que la historiografía renacentista cultivó sin mayores recelos. 41

\section{III}

En lo que se refiere a la composición misma del texto, los vinculos que existen entre los Comentarios y la materia novelesca fueron motivados en parte por la orientación estilǐstica que Garcilaso mantuvo al redactar su obra. Sabemos que los textos del Inca toman como uno de sus referentes principales la escritura refinada que tanto celebró la historiografía del humanismo renacentista. El Quattrocento, al rechazar la mecánica expositiva de los cronistas medievales formuló a su vez una concepción de la historia que establece correspondencias directas entre el virtuosismo narrativo y la verosimilitud de lo relatado. Esa premisa sirve como guỉa en la redacción de la Laudatio Florentine Urbis de Leonardo Bruni y en el Compendio de la historia del Reino de Nápoles de Pandolfo Collenuccio; obra esta última que el Inca cita en la Florida (I, V, cap. VIII) y que también aparece entre sus libros. En la historiografía del humanismo italiano, la glorificación de una cultura o de un reino fue en gran medida un ejercicio literario que adoptaba convencionalismos retóricos muy precisos. ${ }^{42}$ Ese criterio de redacción es el que predomina en la Historia Florentini Populi de Eneas Silvo Piccolomini que el Inca seguramente debió conocer. Una imitación de esa postura narrativa es por cierto la que Garcilaso asume al exaltar las glorias del Cuzco y los refinamientos de la cultura incaica. (I, VI, cap. XX y VII, cap. VIII)

Importa reconocer que una vez consolidada esa formulación retórica de la historia, la escritura supera su función meramente instrumental y pasa a ser contemplada en sî como reflejo o símbolo de lo verosìmil. Ese ideal retórico y nominalista de las artes históricas predominó también en De interpretatione recta de Leonardo Bruni, en el ya mencionado Methodus de Bodin y se desarrolla minuciosamente en la De linguas latinae elegantia de Lorenzo Valla. Y rastros-aunque en menor grado-de esa concepción de la narrativa histórica, se perciben en la Storia d'Italia de Guicciardini a quien tanto admiró Garcilaso. Esos textos, por su belleza, precisión conceptual y vuelo imaginativo, eran sensiblemente afines a la vocación literaria y a la empresa misma que se propuso el Inca. 
Para entender con mayor precisión la postura narrativa del Inca es útil tener en cuenta también que las relaciones espectaculares en torno al mundo americano fueron ofrecidas por los cronistas anteriores a Garcilaso. Su aspiración, por lo tanto, no podía ser la revelación asombrosa de un mundo desconocido. Desprovisto de esas posibilidades, la obra del Inca necesitaba acreditarse principalmente por su refinamiento formal y por las sutilezas y precisión de sus juicios. Ante esas exigencias los Comentarios necesariamente alcanzan una tensión intelectual y un grado de elaboración que incrementan el atractivo de la narración y que posibilitan lecturas diversas del texto.

En los Comentarios esa construcción a veces exquisita del discurso se destaca, por ejemplo, en los episodios que refieren las vicisitudes que sufrieron los españoles en Chile; episodios que el Inca relata de segunda mano y que al cabo de muchos años, resucitan en su memoria para ser reconstruidos con dramatismo espectacular, Garcilaso, con esmero habitual, documenta sus fuentes y a la vez se ampara en una vieja tópica literaria, "la trujo un indio de Chili, escrita en dos dedos de papel, sin firma ni fecha de lugar ni tiempo." (I, VII, cap. XXI) Asǐ, en el próximo capítulo se ofrece la narración casi novelesca de los hechos.

Los españoles salieron a la grita de los indios hermosamente armados, con grandes penachos en sus cabezas y las de sus caballos, y con muchos pretales de cascabeles, y cuando vieron los escuadrones divididos, tuvieron en menos los enemigos, por parecerles que más facilmente romperian muchos pequeños escuadrones que uno muy grande. El capitán indio, viendo los españoles en el campo dijo a los del primer escuadrón: "Id vosotros, hermanos, a pelear con aquellos españoles; y no digo que los venzáis, sino que hagáis lo que pudieredes en favor de nuestra patria; y cuando no podáis más, huid, que yo os socorreré a tiempo.

El relato prosigue de esta manera:

A esta hora un indio, que desde muchacho se había criado con el gobernador Pedro de Valdivia, llamado Felipe, y en nombre indio Lantaru, hijo de uno de sus caciques (en quien pudo más la infidelidad y el amor de la patria, que la fe que a Dios y a su amo debia) oyendo apellidarse los españoles para retirarse, cuyo lenguaje entendía, por 
haberse criado entre ellos, temiendo no se contentasen sus parientes con verlos huir y los dejasen ir libres, salió a ellos dando voces diciendo: "No desmayéis, hermanos, que ya huyen estos ladrones y ponen su esperanza en llegar hasta el paso estrecho. (I, VII, cap. XXIII)

En España, y particularmente en el cirrculo de los Savants de Córdoba que tanto influiría en Garcilaso, habìa prosperado ya ese ideal artïstico de la historia aunque con las restricciones éticas que en general mantuvo la historiografía española. Es esa visión de la historia la que a su manera defendieron Luis Vives y Juan de Valdés y que motivó una corriente de invenciones narrativas y de especulaciones que a la postre hicieron aun más confuso los límites entre el quehacer literario y la historia.

Llevado por sus inclinaciones naturales y por el impacto de sus lecturas, es natural que Garcilaso se sintiera atraído por esa construcción elegante de la narrativa histórica. En los textos de Bruni, Collenucio y Piccolomini, el lenguaje asumia una función inusitada: el discurso en sỉ aparece como pantalla que refleja los procesos vitales de una cultura. El tex to como tal indirectamente se toma como una representación simbólica de la realidad histórica. Aunque no en la misma proporción, la obra de Garcilaso se apoya también en matizaciones lingüìsticas del quechua que al resolver etimologías comunican además el sentido que sus antepasados tuvieron de la historia y de la vida misma. De hecho en varias ocasiones la narración de Garcilaso adquiere un notable sesgo de metalenguaje al comentar y contraponer los valores semánticos del castellano y el quechua: "Por lo cual los historiadores españoles que no supieron esta diferencia, dijeron: 'Los indios entran llorando y guayando en sus templos a sus sacrificios, que huaca eso quiere decir; habiendo tanta diferencia de este significado llorar a los otros, y siendo el uno verbo y el otro nombre." (I, II, cap. V) 43 En los Comentarios estamos, pues, ante una escritura que con frecuencia se desdobla para elucidar, desde su propia hechura, los aspectos más sutiles del proceso histórico y para lograrlo se recurre tanto al análisis lingüistico y el comentario de textos como al epigrama, la imagen y el exemplum. Esa diversidad de funciones evoca de inmediato la concepción retórica de la historia que subyace, por ejemplo, en los textos de Colluccio, Salutati y Petrarca, autor este último, que estuvo representado en la biblioteca del Inca. Nancy S. Struever en su admirable análisis de los textos de Salutati, Guarino de Verona y Leon Battista Alberti ha puesto en evidencia el sentido nominalista y la base 
eminentemente retórica que predomina en esos modelos historiográficos: "Thus the humanists-dice la profesora Struever-are convinced that the use of rhetorically instead of logically oriented discourse leads one into reality through illusion." 44 Al concebir así el discurso de la historia, la palabra adquiere una función doble: es una representación simbólica de la realidad y sỉntesis estructural de la misma. Desde esa percepción lingüîstica de la historia, "If every sentence-agrega la profesora Struever-is a statemente of syntactical relationship, every rhetorically organized sentence is a self-conscious acknowledgement of a macrostructure of relationships between orator and protagonist, audience and ambience." 45 Ese discurso propone tácitamente que todo esquema de una estructura significante del lenguaje puede verse también como esbozo de un contexto cultural. Aunque reconozco que los Comentarios no establecen equivalencias de esa amplitud teórica, conviene recordar, no obstante, que el texto de Garcilaso se apoya sobre una perspectiva lingüïstica que en sỉ autoriza algunos de los aportes documentales más importantes que ofrece el texto. A su manera el Inca trabajó como el historiador humanista que al traducir y explicar los textos clásicos rescataba, a su vez, la sabidurỉa de un pasado glorioso. En última instancia el ángulo crucial de afinidad entre los Comentarios y sus modelos italianos radica, pues, en que el código lingüistico como tal se toma en varios planos como base epistemológica de la realidad.

En resumen, la narración del Inca aparece como una síntesis grandiosa de casi todo lo que se sabía en tiempos de Garcilaso. De ahì, en parte, que su obra haya motivado investigaciones tan diversas. Pero el texto es mucho más que un compendio voluminoso de erudición y observaciones personales. Los Comentarios son además el testimonio intelectual de un hombre que vivió marginado 46 y que quiso ingresar en la historia de su escritura. Es esa urgencia interior la que tantas veces transmutará su lenguaje en un acto de creación. Superadas las valoraciones positivistas que siempre permanecen en la superficie del texto, creo que el contenido imaginativo en la obra del Inca no limita sino que amplìa su valor ya que la escritura en los Comentarios informa tanto a nivel de la cifra como desde su misma expresividad. 47 En último término, me parece indiscutible que la calidad literaria de la narración es lo que en definitiva transforma las categorias estáticas de la historia al darle a la escritura un contexto semántico de mayor riqueza. En los Comentarios el discurso no sólo ofrece una visión deslumbrante de la historia sino que inaugura además una manera americana de sentirla. 


\section{NOTAS}

1. Las controversias en torno a la obra del Inca fueron suscitadas en parte por las observaciones de Marcelino Menéndez Pelayo al afirmar, entre otras cosas, que "la autoridad histórica del Inca Garcilaso ha decaído mucho entre los criticos modernos, y son pocos los americanistas que se atreven a hacer caudal de ella." Historia de la poesía hispanoamericana (Santander, 1948) II, 75-76. John Howland Rowe, al referirse a los procedimientos historiográficos del Inca, señala que "his testimony on religion and history is extremely untrustworthy." Inca Culture of the Time of the Spanish Conquest (New York, 1946), 315. Por su parte, el eminente garcilacista peruano Raúl Porras Barrenechea admite sin reservas que "El traslada a la crónica su sensibilidad de espíritu neoplatónico demostrada ya en la traducción de León Hebreo. Exagerando quizás la posición especulativa del Inca y desvalorizando excesivamente su exactitud histórica, Mariano Ibérico Rodríguez ha calado sutilmente la esencia idealista de la obra de Garcilaso al tratar del imperio incaico. Garcilaso, nos dice Ibérico en su elegante ensayo sobre éste, tuvo una sensibilidad filosófica y poética impregnada de amor por las esencias ideales." El Inca Garcilaso de la Vega (Lima, 1946), 21. Agradezco la ayuda del Vanderbilt University Research Council y del Social Science Research Council que hizo posible parte de las investigaciones que he resumido en este trabajo. Lo que sigue y otros estudios que en breve daré a conocer forman parte de un libro en preparación.

2. Tómese en cuenta por ejemplo, esta observación de Carlos Daniel Valcárcel, “¿Fue Garcilaso un historiógrafo ordenador de datos, o un historiólogo cuyo vuelo conceptual-además de literario-muestra oquedades que señalan una insuficiente información? Garcilaso representa lo mejor de ambas tendencias, subsumidas por su acusada personalidad de historiador auténtico." "Concepto de la historia en los Comentarios reales y en la Historia general del Perú" en Nuevos estudios sobre el Inca Garcilaso (Lima, 1955), 125.

3. El aspecto creativo de los Comentarios se ha comentado en tres estudios fundamentales: José Durand, "El Inca Garcilaso, historiador apasionado," Cuadernos Americanos, LII (1950), 153-168; Juan Bautista Avalle Arce, El Inca Garcilaso en sus Comentarios (Madrid, 1964), 9-33; Alberto Escobar, "Lenguaje e Historia en los Comentarios reales," en Patio de Letras (Lima, 1965), 11-40.

4. Ya en la segunda carta a Maximiliano de Austria, que precede a los Diálogos de amor, el Inca indicaba su proyecto en marcha: "le suplico humildemente que habiendo aceptado este amoroso servicio que es lo que en ellos más se debe estimar, por pequeños o grandes que sean, para acabar de tejer las historias de la Florida y urdir la del Pirú," Obras completas, Edición de P. Carmelo Saénz de Santa María, B.A.E. (Madrid, 1965), 14. Las citas del texto provienen de esta edición. Se indican sucesivamente primera o segunda parte, libro y capitulo. La historiografía moderna designa la segunda parte como Historia general del Perú. Esa denominación es ajena sin embargo a la concepción original de Garcilaso ya que él se refiere exclusivamente a la primera o segunda parte de sus Comentarios.

5. Al comentar sus fuentes y conocimientos de las costumbres incaicas, Garcilaso documenta repetidamente su interés por los hechos que presenció en 
su niñez, "Los curacas ajenos rogaban a mi madre que me mandase les cotejase sus cuentas; porque como gente sospechosa, no se fiaban de los españoles que les tratasen verdad en aquel particular hasta que yo les certificaba de ella, leyéndoles los traslados que de sus tributos me traían y cotejándolos con sus ñudos: y de esta manera supe de ellos tanto como los indios." (I, VI, cap. IX)

6. En lo que se refiere a esos rasgos e intuiciones de la historiografía clásica, véase: A. D. Momigliano, "The Place of Herodotus in the History of Historiography," History, XLIII (1958), 1-3. El subrayado es mio.

7. El subrayado es mïo. Fijémosnos además en la observación que hace Garcilaso en el capítulo anterior, "A semejanza de las fábulas que hemos dicho de los Incas, inventan las demás naciones del Perú otra infinidad de ellas del origen y principio de sus primeros padres, diferenciándose unos de otros, como los veremos en el discurso de la historia." Es claro que la perspectiva histórica del Inca admite, aunque con reservas ocasionales, la materia imaginada como valiosa fuente documental. Muy certeras son por cierto las observaciones que José Gaos ofrece sobre la historicidad del material legendario; observaciones que son notablemente afines a la postura que tomó el Inca. Véase: Los orígenes de la filosofía y de su historia (México, 1968), 22-25. Al comentar los procedimientos de la historiografía en el siglo XVI, el eminente historiador inglés J. H. Elliott, observa que "A los europeos, acostumbrados a los documentos escritos, podía no inspirarles gran confianza la dependencia de la tradición oral, pero al menos la idea no les era completamente extraña. Fernández de Oviedo, al tratar la misma cuestión una generación antes que Acosta, recordaba sagazmente a sus lectores que también los castellanos tenian su historia oral en forma de grandes romances. Habìa también un importante precedente clásico en las historias de Herodoto, cuyos métodos y veracidad eran temas de animados debates en el siglo XVI. Herodoto, cuando investigaba la historia de pueblos extranjeros y bárbaros, tomaba su información de la tradición oral. Así, era posible para los españoles del siglo XVI fiarse de la memoria popular al recoger las historias de los pueblos de América sin pensar que violentaban excesivamente con ello su concepto de un adecuado método histórico." El Viejo y el Nuevo Mundo (Madrid, 1970), 49-50. $\mathrm{La}$ vigencia de lo legendario en la historiografía moderna se ha documentado con singular agudeza en la obra de Leonardo Olschki, Storia Letteraria. delle Scoperte Geografiche (Firenze, 1937). Se discute en esta obra, entre otras cosas, la influencia imaginativa de los romances en las crónicas y documentos relativos al descubrimiento y conquista de América.

8. En su certero trabajo Eugenio Asencio señala que el Inca "cree como Bodin que la mitologìa no es un tejido de vanas fábulas, aunque rechaza la desaforada asimilación de mitos peruanos con creencias cristianas practicadas por ciertos españoles." Y que "nutrido en tales precursores [se refiere a las relaciones de linajes y de anticuarios] Garcilaso corrỉa el riesgo de resbalar hacia el idilio político y el poema genealógico. Las fuentes utilizadas con preferencia, recuerdos de infancia dorados por la lejania; el tema de la glorificación de la patria mezclada con la del propio linaje; la educación anterior, predominantemente literaria; todo le empujaba a un tipo de narración en que mito e historia se 
funden en el crisol de la memoria." "Dos cartas del Inca Garcilaso," Nueva Revista de Filología Hispánica VII (1949), 590-591.

9. Además, en lo que se refiere a esa metodologìa Eugenio Asencio observó también que "El ideal literario que Ambrosio Morales formuló en su Discurso de la lengua castellana, donde defiende un lenguaje copioso y galán, tan remoto de la vulgaridad como de la afectación, corresponde con puntualidad a la práctica del Inca. Este poseìa un don expresivo, un humor delicado, una llaneza elegante, tras la que corrǐa en vano el cordobés. Pero Garcilaso pudo aprender en la Crónica de su protector la importancia que tenia, para un aspirante a historiador, el estudio de las instituciones, la economía, la topografía.Morales en Las antigüedades de las ciudades de España (Alcalá, 1575) enseñó a sus contemporáneos a manejar toda clase de fuentes: literarias, lingüisticas, económicas." Ibid., 592.

10. En breve daré a conocer un estudio que valora las tipologías narrativas que aparecen intercaladas en el texto y la función que éstas desempeñan en la estructura general de la obra.

11. Sobre variantes y razones que motivan esas posturas que el narrador adopta, véase: Marcel Bataillón, Erasmo y España (México, 1950), 609-642. Y el célebre estudio de Américo Castro, "Por qué fue dualmente conflictiva la literatura del siglo XVI" en Hacia Cervantes (Madrid, 1967), 10-25.

12. Para un mejor conocimiento de la formación de Garcilaso es necesario consultar el importante estudio de José Durand, "La biblioteca del Inca," Nueva Revista de Filología Hispánica, II, No. 3 (1948), 239-264. E interesan además, las notas adicionales que ofrecen Bruno Magliorani y Giulio C. Olschki. "Sobre la biblioteca del Inca," NRFH, III, No. 2 (1949), 166-170. Los especialistas que han examinado la obra del Inca admiten sin reservas que aun no conocemos con suficiente exactitud el registro de lecturas que Garcilaso integró en su obra. Dice Durand en el estudio que acabo de citar: "Por lo demás, sobre la influencia de las lecturas en el Inca es poco lo que se ha estudiado, ni desde un punto de vista de las fuentes literarias, ni tampoco para situar al Inca en la historia de las ideas;" 241. Aurelio Miró Quesada, por su parte, al comentar las lecturas del Inca añade: "Para conocer las lecturas italianas del Inca Garcilaso, hay-además de la cita expresa en diversos pasajes de sus obras-el testimonio indirecto, pero sin duda alguna valiosísimo, del inventario de los libros que se encontraron a su muerte en su casa de Córdoba. El testimonio no es del todo preciso desde luego, porque, como se ha observado con acierto, muchos de los libros que tuvo en su mocedad pueden haberse perdido, destruido o eliminado con el tiempo, o pueden haberse quedado, como involuntaria reliquia de un descuido, o abandonados por un cambio de gusto, al trasladarse el Inca a Córdoba, después de haber pasado casi treinta años en Montilla." El Inca Garcilaso y otros estudios garcilacistas (Madrid, 1971), 453.

13. Para una enumeración más amplia de las fuentes historiográficas y literarias, véase el resumen que ofrece Miró Quesada; El Inca Garcilaso, 379-391.

14. Al referirme aquil a las fuentes de los Comentarios interesa subrayar la equivalencia implǐcita que Garcilaso establece entre algunas de sus fuentes litera- 
rias y las historiográficas. Es curiosa, por ejemplo, su observación en torno a la Elegía de varones ilustres de Castellanos, "en las cuales elexías-dice el Incagasta seis cantos de su verdadera y gala historia, aunque escritas en verso." (II; VIII, cap. XIV)

15. Esa utilización de recursos literarios muy diversos y propios de la novela caballeresca, se nota además en la Florida. Véase por ejemplo: (I, cap. X) y (I, II, cap. IV). Como detalle complementarios interesa señalar que Garcilaso conservó hasta su muerte el Palmerino d'Oliva de Ludovico Dolce.

16. La traducción de los Diálogos motivó su lectura de la Instituzione di tutta la vita dell'oumo nato nobile y de otras obras de Alessandro Piccolomini que influirían notablemente en los juicios de Garcilaso y que le encaminan hacia lo que Miró Quesada ha descrito como "el aristotelismo pio." El Inca Garcilaso, 147. En lo que se refiere a la formación intelectual del Inca me parece significativo el hecho de que Garcilaso tomara contacto con la cultura del renacimiento italiano a partir de una experiencia literaria y no desde sus labores historiográficas como tales.

17. Obras completas, I, 9.

18. Aunque no lo sabemos a punto fijo cabe suponer que el Inca conoció entre otros Della natura d'amore de Francesco Cattani da Diacceto. En torno a los fundamentos filosóficos de los Diálogos, véase el valioso estudio de Hirám Peri, "Un predecesor de León Hebreo" en Tesoro de los judíos sefardies, Vol. L (Jerusalen, 1959), 249.

19. Al comentar el impacto de los Diálogos en los Comentarios William D. Ilgen señala con acierto que "Para Garcilaso los Comentarios son nada menos que una proyeción y una idealización de la historia de su patria y de su problemática personal. La conquista es para él, por lo tanto, el intento de realizar en el vasto panorama de la historia un mestizaje ideal entre el Nuevo y el Viejo Mundo. Y la fuente de tan peregrina interpretación de la conquista es precisamente el pensamiento de León Hebreo en los Diálogos de amor, cuyo tema central no es otro que el poder reconciliador del amor como vinculo universal de todo el ser del universo." "La configuración mítica de la historia en los Comentarios reales del Inca Garcilaso de la Vega" en Estudios de literatura hispanoamericana en honor a José J. Arrom, Eds., Andrew P. Debicki y Enrique PupoWalker, (Chape Hill, 1974), 44.

20. El Inca Garcilaso, 337.

21. El Inca Garcilaso de la Vega (Lima, 1946), 21.

22. Ya en la segunda dedicatoria que precede a su traducción de los Diálogos, Garcilaso se ve como intérprete y traductor de un mundo cultural que le pertenece: "Concluída esta relación-dice el Inca-entenderé en dar otra de las costumbres, ritos y ceremonias que la gentilidad de los ingas, señores que fueron de Perú se guardara en sus reinos, para que V. M. las vea desde su origen y principio, escritas con alguna más certidumbre y propiedad de lo que hasta ahora se han escrito." Obras completas I, 11.

23. El empeño de Garcilaso por establecer su autoridad como intérprete y traductor de la cultura incaica data como se verá de sus primeros esfuerzos 
literarios. En su primera dedicatoria a Felipe II que precede a la versión castellana de los Diálogos dice el Inca "porque ni la lengua italiana, en que estaba, ni la española, en que la he puesto, es la mia natural." Obras completas I, 6.

24. Esa fusión de conceptos y la visión retórica de la historia que defienden varios historiadores latinos se discute con ejemplar brillantez en la obra de William Nelson, Fact or Fiction: The Dilemma of the Renaissance Storyteller (Cambridge, Mass., 1973), 1-36. Para observaciones aun más detalladas sobre el mismo tema interesa la conocida obra de Felix Gilbert, Machiavelli and Guicciardini: Politics and History in the Sixteenth Century Florence (Princeton, 1965), 204-229. De gran valor es también el estudio de Wallace E. Ferguson, The Renaissance in Historical Thought: Five Centuries of Interpretation (Boston, 1948), 3-20.

25. En ese contexto es de interés la siguiente observación de Juan Luis Vives: "Hanse de escribir mucho y frecuentemente de los filósofos gentiles y de nuestros santos, pues pueden reportar mucho fruto al linaje humano, así los ejemplos de las virtudes que aquellos alcanzaron y practicaron sin más luz y guía que la Naturaleza o de la heroica probidad que los nuestros obtuvieron por la gracia de Dios." Obra completas (Madrid, 1948), II, 781. La proximidad del Inca a ese concepto ejemplar y medievalista de la historia está presente de diversas maneras en los Comentarios. "Por tres fines-dice Garcilaso-se eternizan en escritos los hechos hazañosos de hombres en paz y letras o en armas y guerra señalados: por premiar sus merecimientos con perpetua fama; por honrar su patria, cuya honra ilustre con ciudadanos y vecinos tan ilustres; para ejemplo e imitación de la posteridad, que avive el paso en pos de la antigüedad, siguiendo sus batallas, para conseguir sus victorias." (II, Prólogo a los indios y mestizos, Obras completas, 3.)

26. Citado por Américo Castro, Hacia Cervantes, 94.

27. El Inca cita por ejemplo la Crónica general de Alfonso el Sabio, (II, I, cap. III); las crónicas de Fernando el Santo, Enrique II, Enrique III y Juan II (II, I, caps. III y IV).

28. Refiriéndose a la visión histórica del Inca, Eugenio Asencio señala en otra parte que "La concepción de las tres edades que sirve de esqueleto a los Comentarios, recuerda, claro es, la idea agustiniana de una construcción gradual de la ciudad de Dios," "Dos cartas del Inca," 589. Para ver, a nivel formal, la proximidad que existió en la Edad Media entre la prosa de ficción y la historia consúltese el importante estudio de la profesora Frida Weber de Kurlat, "Estructura novelesca del Amadis de Gaula," Revista de Literatura Moderna, No. 5 (1965), 29-54.

29. Otras secciones de los Comentarios en que se aprovechan esos recursos de la historiografía clásica aparecen en: (I, II, cap. XVI), (I, II, cap. XXI) y (II, V, cap. III).

30. Ver: J. H. Elliott, El Viejo Mundo, 70.

31. Interesan en ese sentido las observaciones que aporta Henry Thomas en Spanish and Portuguese Romance of Chivalry (Cambridge, 1920), 195-199; y 
Werner Krauss en "Die Kritik des Siglo de Oro am Rittex-und Sehäferroman," Gesammelte Aufsätze zur Literatur-und Sprachwissenschaft (Frankfurt, 1949), 152-176.

32. Edward C. Riley por su parte apunta que: "La confusión flagrante entre historia y ficción, las declaraciones en que se proclamaba que las narraciones eran verdaderas al pie de la letra y los artificios que se usaban para encarecer esta pretensión: todo ello podria haber estado justificado si existiera un propósito claro. Pero ese propósito no existe. Las sorprendentes observaciones de los autores acerca de sus propias narraciones, y su manera de manejarles, muestran con frecuencia la más extraña mezcla de ingeniosidad e ironía, una especie de convicción a medias que es sintomática de la degeneración del género." Teoría de la novela en Cervantes (Madrid, 1966), 47. De igual interés son por ejemplo las aclaraciones que sobre el mismo tema ofrece Alban K. Forcione en su obra Cervantes Aristotle and The Persiles (Princeton, 1970), 20-48.

33. Cito por la edición de Martĭn de Riquer (Barcelona, 1958), I, cap. 47.

34. Obras completas, 3.

35. Erasmo en España, 622.

36. Al comentar los rasgos literarios de la Florida Miró Quesada señala: "En otras partes, lo que se manifiesta en la Florida es el gusto por las narraciones al estilo de las novelas italianas. Hay escenas de fiestas, enaltecidas por la lindeza de la gala (libro I, cap. XI), en las que se despliega, en fino juego, una cortesanìa medieval y renacentista al mismo tiempo." El Inca Garcilaso, 337.

37. Erasmo, 622.

38. B. A. E. III, 187. Otros juicios de interés se discuten en el agudo trabajo de Bruce W. Wardropper, "Don Quixote: Story or History," Modern Philology LXIII (1965), 1-11.

39. William Nelson refiriéndose precisamente a la amplitud de criterio con que se juzga lo verosìmil en el Renacimiento señala: "Typically, therefore, verosimilitude was offered as the quality of good fiction that differentiated it from the wild dreams of medieval romances on the one hand and made it comparable or even superior in value to veritable history on the other. This might be construed as advocacy of 'realism,' a quality not much in evidence in Renaissance literature," Fact or Fiction, 50. Esa convivencia de procedimientos históricoliterarios, se transplanta en las censuras vehementes que Pero Mexĩa, Diego Gracián de Aldrete y Juan de Valdés hacìan a las fabulaciones caballerescas. Este último comenta que "siendo esto assì que los sirven mentiras las deven escribir de suerte que se lleguen, quanto fuere possible, a la verdad, de tal manera que pueden vender sus mentiras por verdades, nuestro autor de Amadís unas vezes por descuido y otras no sé por qué dize cosas tan a la clara mentirosas, que de ninguna manera las podeřs tener por verdaderas.' Diálogo de la lengua (Madrid, 1964), 177. Aparte de la confusión inherente en esas objecciones de Valdés, cabe señalar que inclusive Pero Mexía en su fervor historicista aprovechó los recursos expresivos de la narrativa de ficción. Véase su Historia del Emperador Carlos V, 
ed. J. de Mata Carriazo (Madrid, 1945), 7 y siguientes. Sabemos además cuanto admiró el Inca la obra de Mexía.

40. Ver: Maria Rosa Lida de Malkiel: "Fray Antonio de Guevara, Edad Media y Siglo de Oro español," Nueva Revista de Filología Hispánica, VII (1945), 357.

41. Véase: Hans Baron, From Petrarca to Leonardo Bruni (Chicago, 1968), 151-171.

42. El ilusionismo renacentista en la retórica historiográfica y en las artes en general ha sido analizado por E. H. Gombrich en su obra Art and illusion (Londres, 1960), 101-116. La fuente primaria y de mayor interés en todos los órdenes es el texto de León Battista Alberti, On painting, trad., J. Spencer, (Londres, 1956), 70 y siguientes. Ver además Hans Baron, Ibid., 152.

43. Véanse los extensos comentarios que sobre estos temas hace Garcilaso: (I, VI, cap. XI), (I, I, cap. XIX).

44. The Language of History in the Renaissance (Princeton, 1970), 77. Un lúcido contraste entre los mecanismos de la prosa histórica y la novela se ofrece en el estudio de Roman Ingaden, "Marginal Commentary on Aristotle's Poetics," Journal of Aesthetics and Art Criticism XX (1961-1962), 162, 173.

45. Ibid., 76. En otra parte la profesora Struever indica que para Salutati por ejemplo: "The distinction between fabula and historia is a simple intention, that both are figurative language, but history has the additional advantage of truth;" 75. Afirmación que dicho sea de paso, está muy próxima a los postulados más recientes de la crítiça. Consúltese por ejemplo, "Las realidades formales de la obra" de Jean Rousset y otros ensayos que aparecen en Los caminos actuales de la crítica (Madrid, 1967), 83-96.

46. La encrucijada del Inca fue descrita por Durand con singular agudeza al decir: "Para él la historia es una apasionada contemplación del destino de su pueblo, del de su misma sangre, del suyo individual." "El Inca historiador," 151. Ese esfuerzo también compensaba la desolación en que vivió; a ese aislamiento se refiere el Inca en una carta dirigida a Juan Fernández Franco en que alude una vez más a su intimidad pero en esta ocasión con una nota de amargura: "hasta que la ingratitud de algún principe y ninguna gratificación del Rey me encerraron en mi rincón." Asencio, "Dos cartas ... " 585.

47. Es justo indicar que Luis A. Arocena en su estudio El Inca Garcilaso y el humanismo renacentista (Buenos Aires, 1949) fue el primer especialista que analizó brevemente algunos rasgos estilísticos de los Comentarios, 47-48. 
